NASA Technical Memorandum 105700

\title{
Optimization of Armored Spherical Tanks for Storage on the Lunar Surface
}

D.J. Bents and D.A. Knight

Lewis Research Center

Cleveland, Ohio

Prepared for the

27th Intersociety Energy Conversion Engineering Conference

sponsored by the SAE, ACS, AIAA, ASME, IEEE, AIChE, and ANS

San Diego, California, August 3-7, 1992 
Optimization of Armored Spherical Tanks for Storage on the Lunar Surface

\author{
D.J. Bents and D.A. Knight \\ National Aeronautics and Space Administration \\ Lewis Research Center \\ Cleveland, Ohio 44135
}

\section{ABSTRACT}

A redundancy strategy for reducing micrometeroid armoring mass is investigated, with application to cryogenic reactant storage for a regenerative fuel cell (RFC) on the lunar surface. In that micrometeoroid environment, the cryogenic fuel must be protected from loss due to tank puncture. The tankage must have a sufficiently high probability of survival over the length of the mission that the probability of system failure due to tank puncture is low compared to the other mission risk factors. Assuming that a single meteoroid penetration can cause a storage tank to lose its contents, two means are available to raise the probability of surviving micrometeoroid attack to the desired level. One can armor the tanks to a thickness sufficient to reduce probability of penetration of any tank to the desired level; or add extra capacity, in the form of spare tanks, that results in survival of a given number out of the ensemble at the desired level. In this paper a combination of these strategies (armoring and redundancy) is investigated. The objective is to find the optimum combination which yields the lowest shielding mass per cubic meter of surviving fuel out of the original ensemble.

The investigation found that, for the volumes of fuel associated with multikilowatt class cryo storage RFC's, and the armoring methodology and meteoroid models used, storage should be fragmented into small individual tanks. Larger installations (more fuel) pay less of a shielding penalty than small installations. For the same survival probability over the same time period, larger volumes will require less armoring mass per unit volume protected.

\section{INTRODUCTION}

Construction and operation of a manned lunar base will require large amounts of liquids and compressed gas to be stored on-site in a manner that is conveniently accessible yet reasonably well protected against catastrophic loss. A solar powered base, for example, will have a regenerative fuel cell (RFC) that must produce and store large quantities of hydrogen and oxygen which are subsequently consumed for power during the long lunar night. Figure 1 shows a $20 \mathrm{kWe}$ lunar base power system based on cryogenic reactant storage. This is in addition to the reactant/propellant stores anticipated for lunar excursion vehicles (LEV) and fuel cell powered surface rovers, and water and air storage for environmental control and life support.

These reactants would be stored in tanks, originally transported to the site during emplacement. Reactant storage tanks for the $20 \mathrm{kWe}$ system can be seen in the foreground. From an emplacement standpoint it is most convenient to simply place the tanks on the surface in a "tank farm" where access and interconnection are easy. However, surface emplacement leaves them exposed to meteoroid attack. On the other hand, burying or covering the tanks with regolith will require more site preparation, including excavation, which means that heavy equipment must be brought to the site beforehand.

If surface emplacement is chosen, a strategy of protection against micrometeoroid attack, either by armoring the tanks or adding spare capacity in the form of redundant tanks, must be pursued. Given that a certain minimum amount of storage capacity is required on-site for the entire duration of the mission, the tank farm architect must choose how many tanks to partition the reactant inventory into, how much extra inventory will be needed, and how much armoring will be required to achieve the desired level of protection. Figure 2 illustrates three possible strategies that could be used, as an example. The combination of armoring and redundancy that is chosen will determine the mass penalty that must be paid to ensure meteoroid survival, which can be compared against the mass of equipment that would be needed to bury the tanks.

Since this penalty should be reduced to a minimum, it is desirable to find what combination of armoring and redundancy will yield the minimum armoring mass per unit of protected (i.e., surviving) storage volume. Storage volume is the criteria because the stored substance will either be incompressible, or stored under a pressure (tank volume per unit of mass stored) that is already fixed by critical point considerations or user parameters of the system downstream, and not within the purview of the tank farm architect.

The problem is treatable by analysis methods similar to those used for meteoroid armoring of radiators, except that the quantity of interest is no longer exposed surface area, but the volume which is enclosed by that exposed surface. The object is to determine the optimum combination of redundancy and 
armoring which minimizes the weight of all tank armoring, divided by the surviving storage volume.

\section{ANALYSIS}

This investigation examined armoring/redundancy strategies in order to find the combination which gives the lowest armoring mass penalty per unit of protected (i.e., surviving) storage volume versus the level of protection specified. This was done by treating the lunar tank farm as an ensemble of $\mathrm{N}$ tanks, of which a given number $\mathrm{K}$ would have to survive meteoroid attack storing the desired quantity of material. Survival probability (probability of no puncture for K out of $\mathrm{N}$ tanks) depends on the number of tanks exposed, the exposed surface of each tank, meteoroid flux distribution and the exposure period.

It was assumed that tank failures were independent; that is, failure of an individual tank does not cause the failure of an adjacent tank and furthermore, there was no effect of shielding of individual tank by adjacent tanks. Tanks were assumed to be spherical and of equal size. To be applicable to both liquid or pressurized gas storage, only the armoring was considered, not the container or its contents. This assumes a meteoroid strike that punctures the armor will also puncture the container causing it to leak (liquid container) or burst (pressure vessel).

The meteoroid flux was modeled from the near earth flux distribution shown in Fig. 3. ${ }^{3}$ This flux would be reduced on the lunar surface by a moon body shielding factor of one half. An average meteoroid velocity of $20 \mathrm{~km} / \mathrm{sec}$ was assumed. Because of their much lower velocity compared to meteoroids, lunar ejecta particles were not considered in the analysis.

Two meteoroid armoring methods were considered: (1) armoring based on threshold penetration of a single ductile plate, ${ }^{4}(2)$ threshold penetration of a bumpered wall according to the method of ${ }^{5}$ which divides the armoring thickness into to a thin bumper wall and a thicker penetration barrier some distance behind the bumper. This reference expresses relative thicknesses and spacing between the bumper and barrier in terms of the number of "equivalent sphere diameters" of the penetrating meteoroid which was based on light gas gun data using aluminum spheres. For purposes of this analysis, the thickness and spacing relationship that yielded minimum shield mass per unit area, shown in Fig. 4, was used directly assuming the bumper to wall spacing was small compared to tank radius so that the effect of tank curvature is negligible. Bumper to wall spacing of 50 equivalent sphere diameters $(\mathrm{S} 1 / \mathrm{d}=50)$ was considered for comparison to single wall armoring. The armoring material was assumed to be aluminum in all cases. The exposure period considered was 7 years.

Table I summarizes the cases that were considered. These cases were calculated via a step-by-step iterative procedure, automated through a BASIC computer program that computes the radius, area, volume, shield thicknesses, and survival probability of a set of $\mathrm{N}$ tanks ( $\mathrm{K}$ of which must survive) for any given meteoroid mass. Based on the survival probability of the $\mathrm{N}$ tank ensemble that results, the meteoroid mass can be either increased or decreased in order to match the desired meteoroid survival probability. Details of this methodology, as illustrated in Fig. 5, are presented in Appendix A. Minimum armoring mass was obtained by exercising this procedure over the full range of $\mathrm{K}$ out of $\mathrm{N}$ for each ensemble value $\mathrm{N}$ to find minimum armoring mass cases for each $\mathrm{K}$. Then the lowest minimum mass case and corresponding $\mathrm{K}$ out of $\mathrm{N}$ was selected. These selected cases were compared as shown below.

\section{RESULTS AND DISCUSSION}

Figure 6 shows typical results for minimum mass and "minimum mass $\mathrm{K}$ out of $\mathrm{N}$ " for 100 cubic meters of surviving volume (single wall armoring). Specific armoring mass (armoring mass per unit of protected, i.e., surviving, storage volume) is plotted against the ensemble number of tanks that were chosen. Although represented graphically with increasing $\mathrm{N}$, these data are discrete points not samples of a curve. The number inscribed in each symbol represents the surviving number of tanks $\mathrm{K}$ out of $\mathrm{N}$ which gave minimum armoring mass. As might be expected, a higher survival probability level always requires more armoring. But this data illustrates the incentive for dividing up a fixed volume into many increments, even though the actual amount of tankage and fuel which must be emplaced exceeds the original volume by a fraction $(\mathrm{N}-\mathrm{K}) / \mathrm{N}$. Similar trends were observed in the other cases studied (minimum mass and "minimum mass $\mathrm{K}$ out of $\mathrm{N}$ " for a given protected volume, survival probability and armoring method). For example, Fig. 7 shows the same general result as Fig. 6 when bumpered wall armoring (bumper to wall spacing $\mathrm{S} 1 / \mathrm{d}=50$ ) is substituted for single wall armoring. Note how the armoring mass has decreased. Although bumpering can dramatically reduce armoring mass, as the comparison of Fig. 8 shows, it does not appear to change the armoring mass versus redundancy choice (K out of $\mathrm{N}$ ).

Similar trends were observed for all the cases (minimum mass and "minimum mass $\mathrm{K}$ out of $\mathrm{N}$ " for a given protected volume and survival probability).

The scaling effects of storage volume on specific armoring mass should also be mentioned. For a given desired survival probability, larger storage volumes incur a smaller meteoroid armoring penalty than small volumes. This is shown in Fig. 9. There is a beneficial scaling effect when larger volumes are stored. Reduced to the minimum, specific armoring mass appears to vary logarithmically with the inverse of volume. Again, similar trends were observed for the other cases, regardless of the survival probability level desired or armoring method chosen.

\section{CONCLUSIONS}

Dividing the protected volume into larger numbers of smaller tanks reduces armoring mass. Most of the benefit can be achieved with reasonably small values of N. For example, desired survival probabilities as high as 0.999 can be obtained when the ensemble $\mathrm{N}$ is 15 to 20 tanks.

The optimum $\mathrm{K}$ out of $\mathrm{N}$ fraction which minimizes armoring mass appears to be roughly 0.62 to 0.65 with increasing N. This is a redundancy of about 54 percent. This contrasts with the 20 percent mass optimized redundancy/armoring 
minimum reported for flat plate radiator surfaces similarly exposed. ${ }^{6}$

Meteoroid armoring scales favorably with size, varying logarithmically with the inverse of the protected volume.

For all storage volumes considered, and the desired survival probabilities lying within our range of interest, the tank armoring/redundancy tradeoff data scale smoothly and show the same trends regardless of the meteoroid armoring method that is chosen. When combined with estimates for the tankage (containment vessel) itself and its contents, the specific armoring mass data presented herein may be used to estimate size, distribution and armoring of a tank farm deployed on the lunar surface.

\section{APPENDIX A}

\section{CALCULATIONS AND PROCEDURE}

Cases were calculated using the following step-by-step iterative procedure, beginning with specification of the storage volume (V) to be protected, the exposure time (T) and the desired tank ensemble survival probability (Psen). Next, the number of tanks $(\mathrm{N})$ was selected, determining the volume of each tank $(\mathrm{v}=\mathrm{V} / \mathrm{N})$. $\mathrm{N}$ may range from 1 to an arbitrarily selected upper bound (ensembles up to 20 tanks were considered). The number of tanks (K) required to survive was then chosen and the radius of each tank was calculated:

$$
\mathbf{r}=\left(\frac{3 \mathrm{v}}{4 \pi}\right)^{0.333}
$$

Next the mass (m) of the micrometeoroid was considered, from which the corresponding meteoroid flux was calculated from: ${ }^{3}$

$$
\begin{aligned}
& \mathrm{f}=4.2658 \times 10^{-15} \mathrm{~m}^{-1.213} \\
& (\mathrm{~m} \text { expressed in } \mathrm{gm})
\end{aligned}
$$

This flux will be reduced by half on the lunar surface, due to body shielding.

For each meteoroid, the armoring thickness needed to just stop penetration was calculated, either from: ${ }^{4}$

$$
\text { th }=0.2588836 \mathrm{~m}^{0.352} \text { (single wall shield) }
$$

for the single wall case, or from Ref. 5 for a bumpered wall shield:
Calculate diameter of equivalent aluminum sphere

$$
\begin{aligned}
\mathrm{d}(\text { in. } \mathrm{cm}) & =2\left(\frac{3 \mathrm{~m}}{4 \pi \times 2.6989}\right)^{0.333} \\
& =0.8911 \mathrm{~m}^{0.333}
\end{aligned}
$$

and use minimum mass bumper-wall distribution and spacing (Fig. 4)

\section{Choose}

$$
\begin{aligned}
& \mathrm{S} 1 / \mathrm{d}=50 \\
& \mathrm{t} 1 / \mathrm{d}=0.07 \\
& (\mathrm{t} 1+\mathrm{t} 2) / \mathrm{d}=0.2972 \\
& \mathrm{t} 2 / \mathrm{d}=0.2272 \\
& \mathrm{~S} 1=50 \mathrm{~d} \\
& \mathrm{t} 1=0.07 \times 0.8911 \mathrm{~m}^{0.333} \text { (bumper wall) } \\
& \mathrm{t} 2=0.2272 \times 0.8911 \mathrm{~m}^{0.333} \text { (main penetration barrier) }
\end{aligned}
$$

which results in:

$$
\mathrm{th}=\mathrm{t} 1+\mathrm{t} 2+\mathrm{S} 1 \text { for the bumpered case. }
$$

Then the exposed area of an individual tank was calculated:

$$
\mathrm{Ar}=4 \pi(\mathrm{r}+\mathrm{th})^{2}
$$

and the probability of zero hits for meteoroids greater than $\mathrm{m}$ grams was calculated:

$$
\text { Psit }=\mathrm{e}^{-0.5 \text { FArT }}
$$

where $\mathrm{T}$ was the length of the mission (in seconds). The survival probability of $\mathrm{N}$ tanks ( $\mathrm{k}$ of which must survive) was given by the Binominal Distribution:

$$
\text { Psen }=\sum_{i=K}^{N} \frac{N !}{i !(N-i) !} \operatorname{Psit}^{i}(1-P s i t)^{N-i}
$$

The armor mass for the $\mathrm{N}$ tanks that results was given by the individual tank armoring mass:

$$
\text { Mait }=1.333 \pi \times 2.6989\left((r+t h)^{3}-r^{3}\right)
$$


for single walls, or

$$
\begin{aligned}
\text { Mait }= & 1.333 \pi \times 2.6989\left((r+t 1+t 2+S 1)^{3}\right. \\
& \left.-(r+t 2+S 1)^{3}+(r+t 2)^{3}-r^{3}\right)
\end{aligned}
$$

for bumpered walls; and by multiplying times the number of exposed tanks.

$$
\text { Maen = Mait }{ }^{\prime \prime} \mathrm{N}
$$

If the resulting survival probability (Psen) was greater than the desired value, the meteoroid mass (m) was reduced (reducing the shield thickness, shield mass, and survival probability) and the procedure (steps 2 through 6 ) repeated. Conversely, if the survival probability was lower than the desired value, the meteoroid mass was increased, which decreased the hit probability and increased survival probability. Variation of meteoroid mass was performed iteratively until convergence occurred. To find the optimum combination of tanks and spares for a desired ensemble survival probability, for example, the relative shield masses to unit volume was calculated for spares ranging from 0 to $\mathrm{N}-1$. Table A-I is an example case where $\mathrm{N}=8$ and $\mathrm{V}=100 \mathrm{~m}^{3}$. When there are eight small tanks and no spares, the shield thickness must

Table A-I.-Armoring/Spares for $100 \mathrm{~m}^{3}$, Survival Probability $=0.999$

\begin{tabular}{|c|c|c|c|}
\hline $\begin{array}{c}\text { Number } \\
\text { of } \\
\text { tanks }\end{array}$ & $\begin{array}{c}\text { Number } \\
\text { of } \\
\text { spares }\end{array}$ & $\begin{array}{c}\text { Relative } \\
\text { shield } \\
\text { mass }\end{array}$ & $\begin{array}{c}\text { Relative } \\
\text { shield } \\
\text { thickness }\end{array}$ \\
\hline 8 & 0 & 320.25 & 0.140 \\
8 & 1 & 104.91 & .045 \\
8 & 2 & 75.94 & .030 \\
8 & 3 & 67.96 & .024 \\
8 & 4 & 68.14 & .020 \\
8 & 5 & 74.79 & .018 \\
8 & 6 & 92.43 & .017 \\
8 & 7 & 145.77 & .017 \\
\hline
\end{tabular}

be large since all eight tanks must survive. When only one of eight tanks must survive, the shield thickness can be small, but the tanks themselves are very large. Minimum shield mass per unit volume in this case occurs when the system has eight tanks and three spares.

\section{REFERENCES}

1. L. Kohout, "Cryogenic Reactant Storage for Lunar Base Regenerative Fuel Cells," Space Power, Vol. 8 No. 4 November 1989

2. S. Girrens, "Design and Development of a Titanium Heat-Pipe Space Radiator," LANL Report No. LA-9251-MS, UC-38, March 1982

3. B. Cour-Palais, et al, "Meteoroid Environment Model (near Earth to lunar surface)," NASA SP-8013, National Aeronautics and Space Administration, March 1969

4. V. Frost, "Meteoroid Damage Assessment," NASA SP-8042, National Aeronautics and Space Administration, May 1970

5. J. Lundberg, P. Stern, and R. Bristow, "Meteoroid Protection for Spacecraft Structures," Boeing Co., Seattle, WA, D2-24056, Oct. 1965 (NASA CR-54201)

6. R. English and D. Guentert, "Segmenting of Radiators for Meteoroid Protection," Journal American Rocket Society,

\begin{tabular}{|c|c|}
\hline $\begin{array}{l}\text { Surviving stored } \\
\text { volumes }\end{array}$ & 10,100 , and $1000 \mathrm{~m}^{3}$ \\
\hline $\begin{array}{l}\text { Survival probability } \\
\text { levels }\end{array}$ & $\begin{array}{c}\text { Seven year survival probability } \\
0.990,0.995 \text {, and } 0.999\end{array}$ \\
\hline $\begin{array}{l}\text { Ensemble number of } \\
\text { tanks } N\end{array}$ & From 1, up to 30 tanks \\
\hline Number surviving $\mathrm{K}$ & $\begin{array}{l}\text { From } 1 \text {, up to } \mathrm{N}, \mathrm{K} \text { selected to } \\
\text { minimize ensemble armoring } \\
\text { mass }\end{array}$ \\
\hline Meteoroid flux model & $\begin{array}{l}\text { NASA SP- } 8013 \text { near Earth flux } \\
\text { distribution reduced by } \\
50 \text { percent lunar body shield- } \\
\text { ing factor }\end{array}$ \\
\hline Armoring methods & $\begin{array}{l}\text { Single wall, NASA SP-8042 thin } \\
\text { ductile plate (aluminum) } \\
\text { Bumpered wall, NASA CR-54201, } \\
\text { minimum mass, S1/d }=50\end{array}$ \\
\hline
\end{tabular}
August 1961

Table I.-Lunar Tank Farm Study 


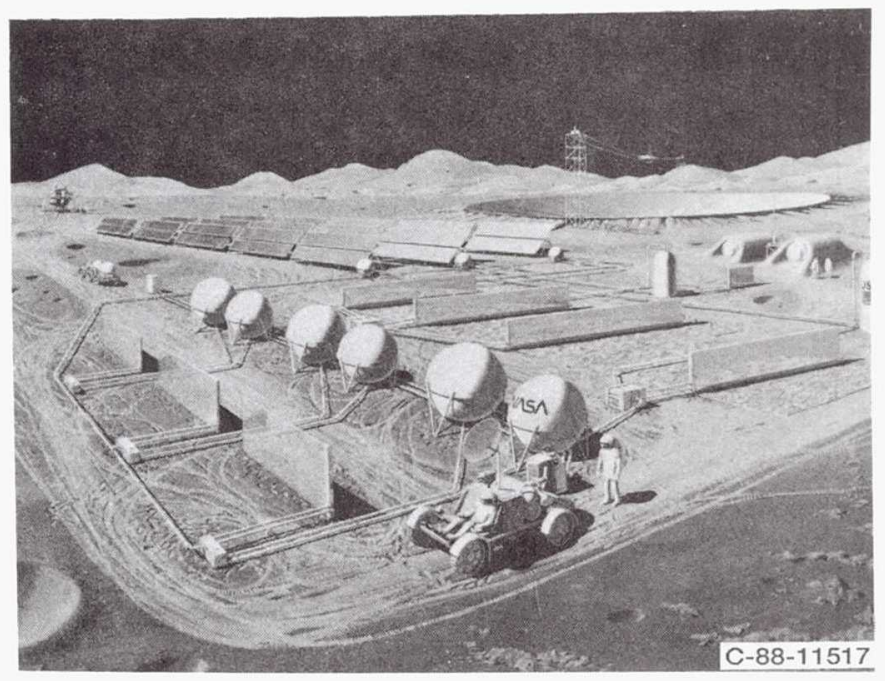

Figure 1.-20kWe PV/RFC power system for lunar base - - cryogenic reactant storage (from ref. 1)

Survival Probability 1 tank $=0.999$

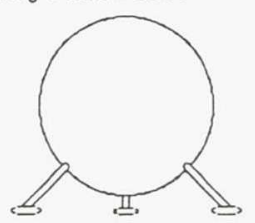

1 tank, $100 \mathrm{~m}^{3} 3$, no spares

Survivel Probability eny tank $=0.982$
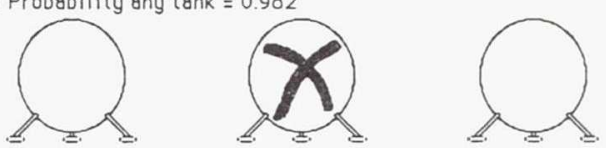

3 tanks, $50 \mathrm{~m}^{-3} 3$ each, 2 out of 3 surviving

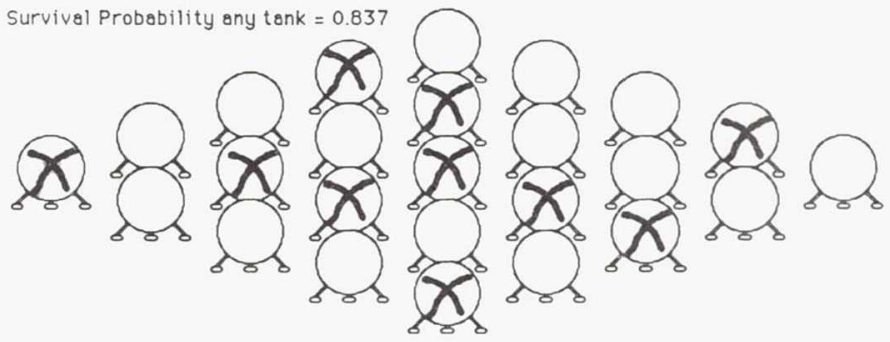

25 tanks, $6.67 \mathrm{~m}^{-3}$ each, 15 out of 25 surviving

Figure 2.-Three possible ways to assure 0.999 survival probability for 100 cubic meters of storage. 


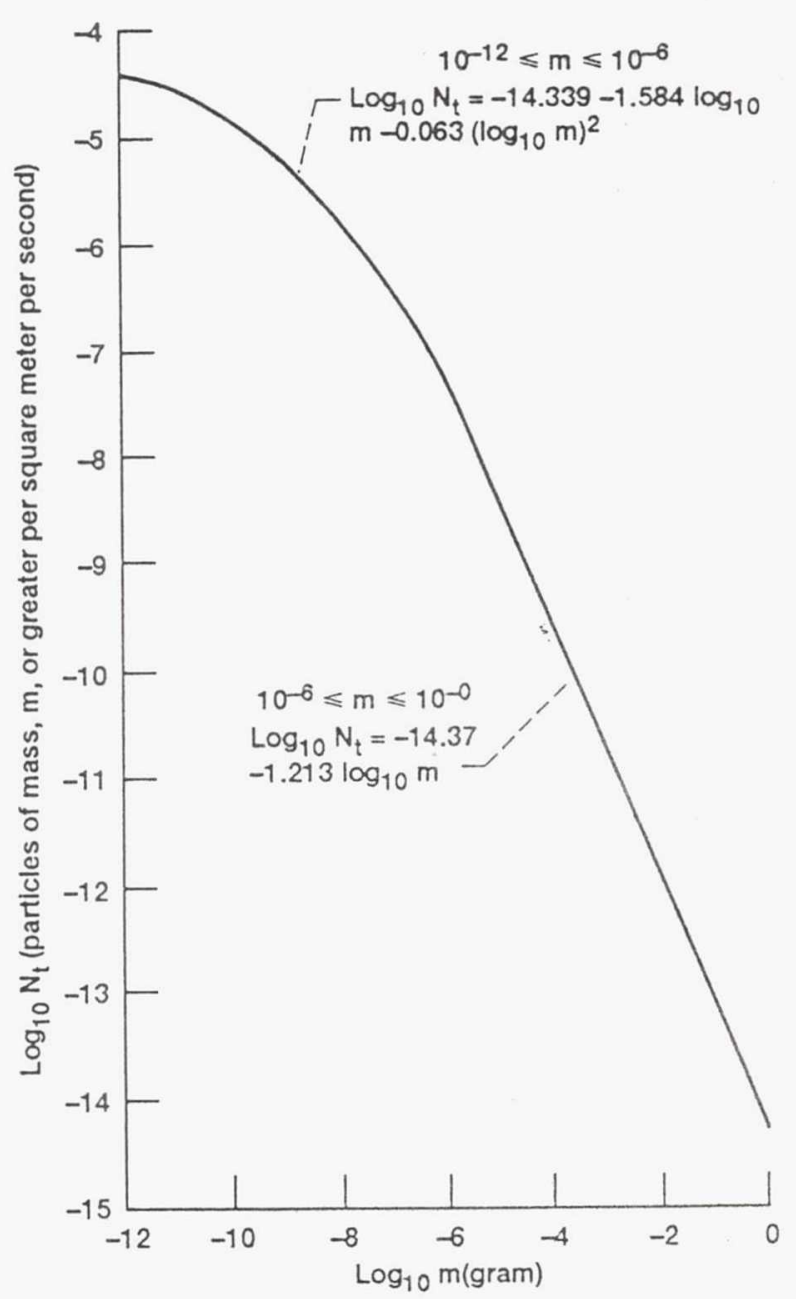

Figure 3.-Average cumulative total meteoroid flux-mass model for 1 A.U. from ref. 3 (NASA SP8013).

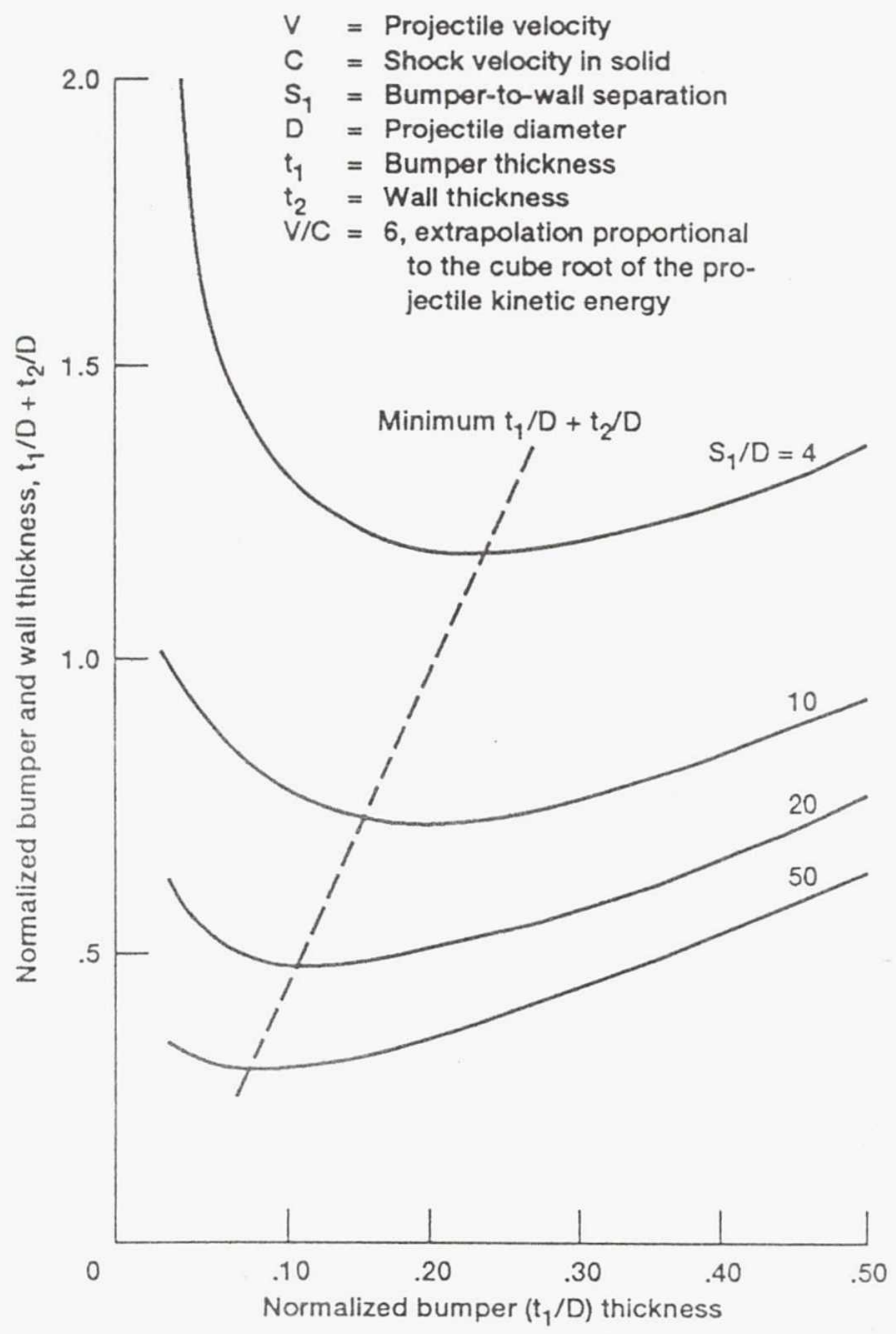

Figure 4.-Minimum weight two-sheet barrier to prevent penetration (from ref. 5). 


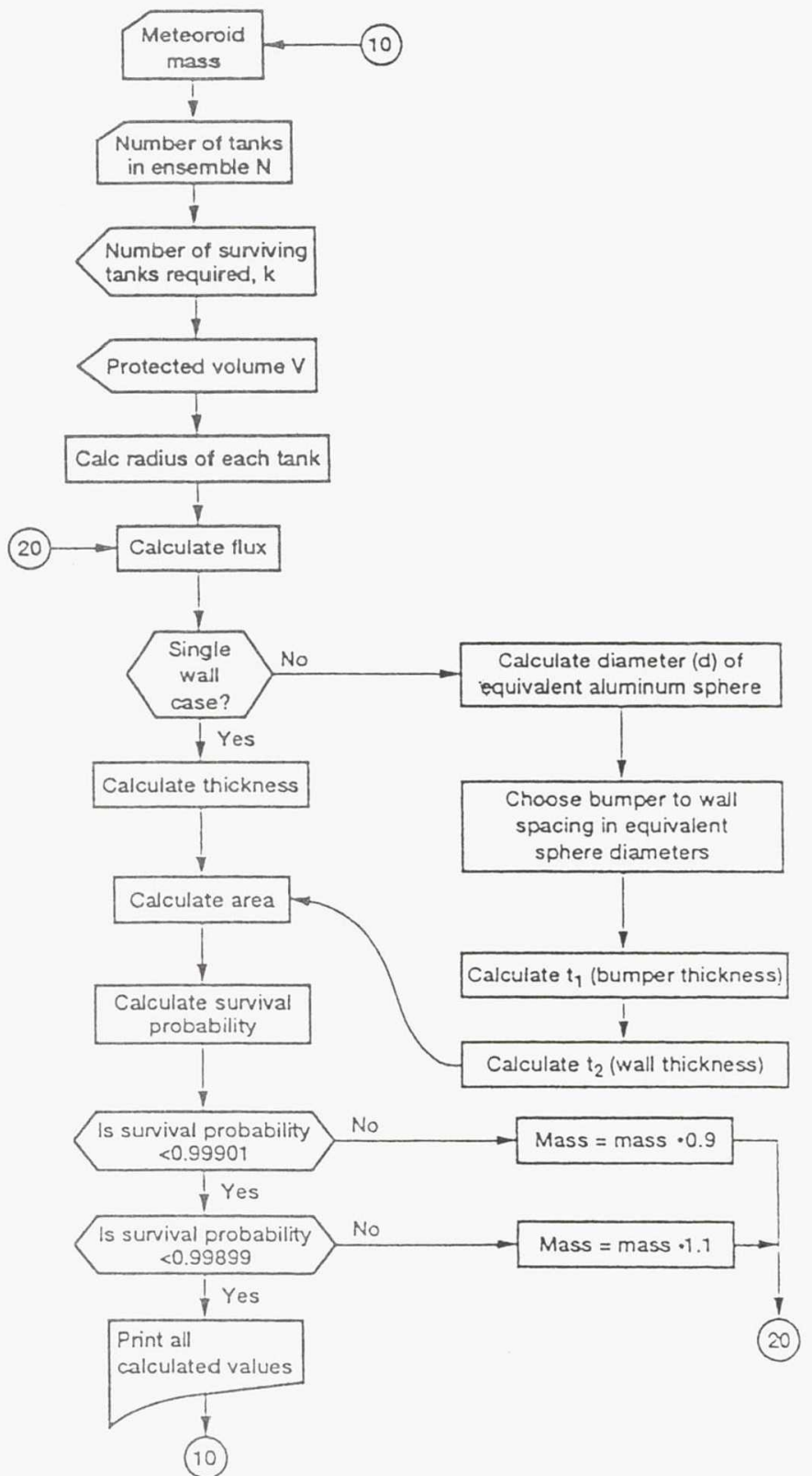

Figure 5.-iterative procedure to compute tank armoring mass and ensemble survival probability.

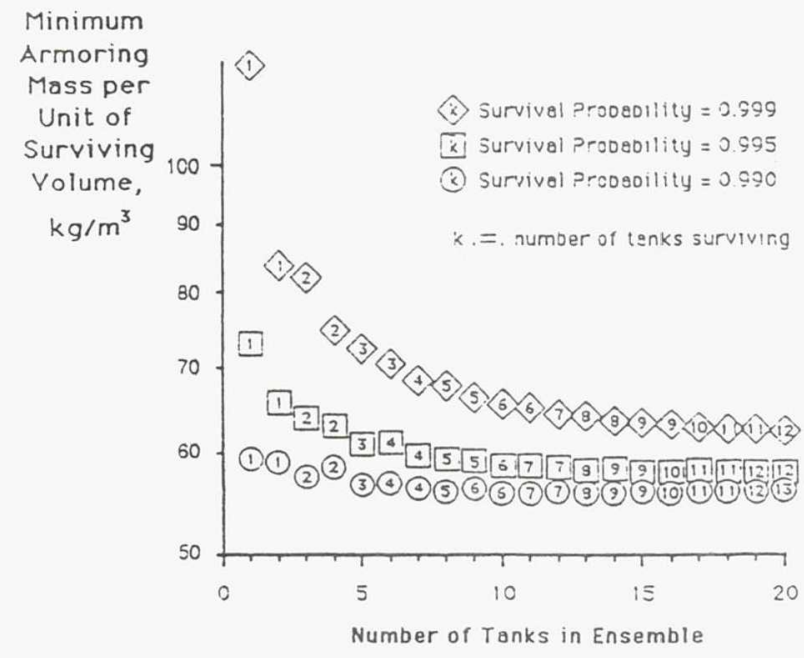

Figure 6. - Single wall armoring, seven year mission, 100 cubic meters surviving.

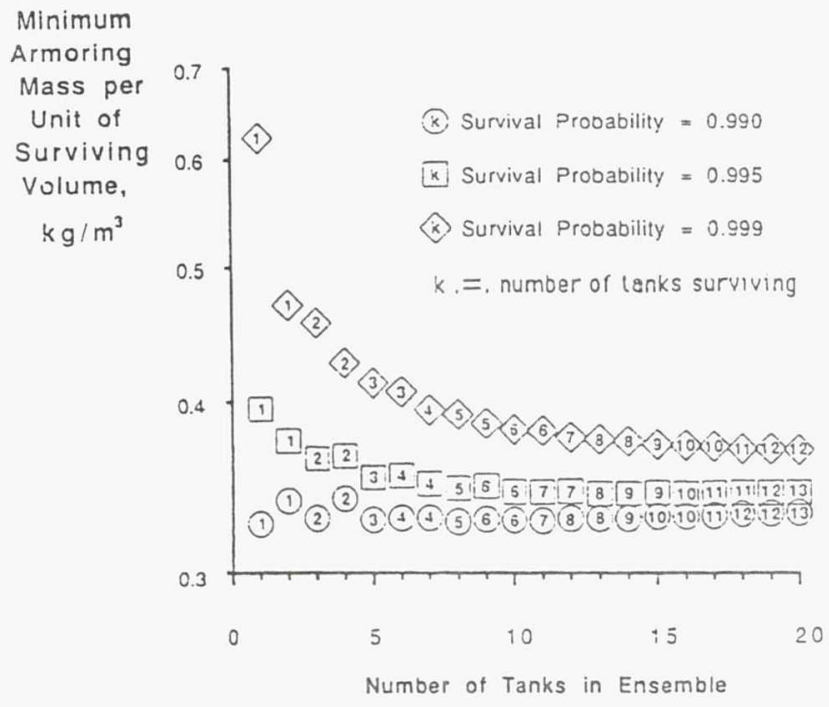

Figure 7.-Bumpered wall armoring $(S 1 / d=50)$, seven year mission, 100 cubic meters surviving.

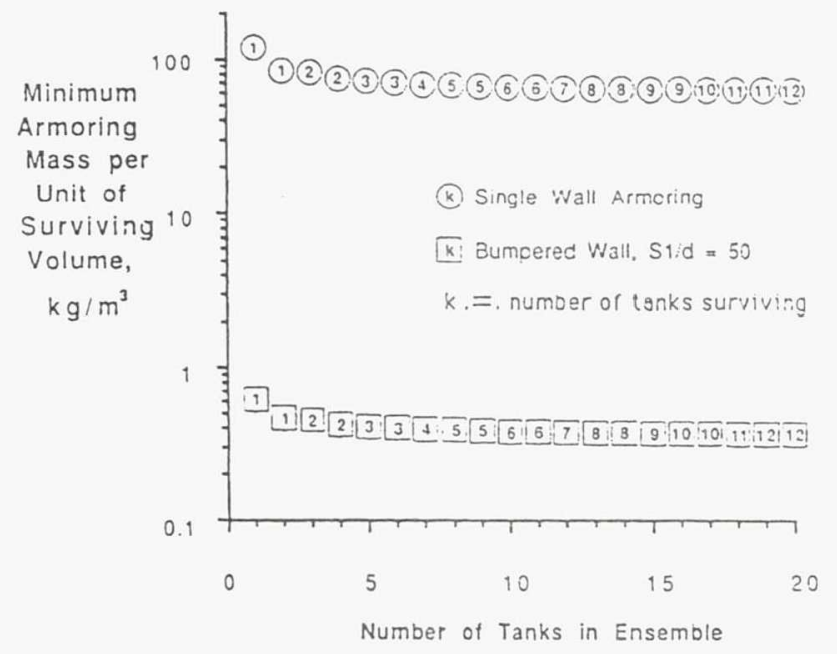

Figure 8.-Bumpered wall versus single wall armoring, 100 cubic meters surviving, seven year mission, 0.999 survival probability. 


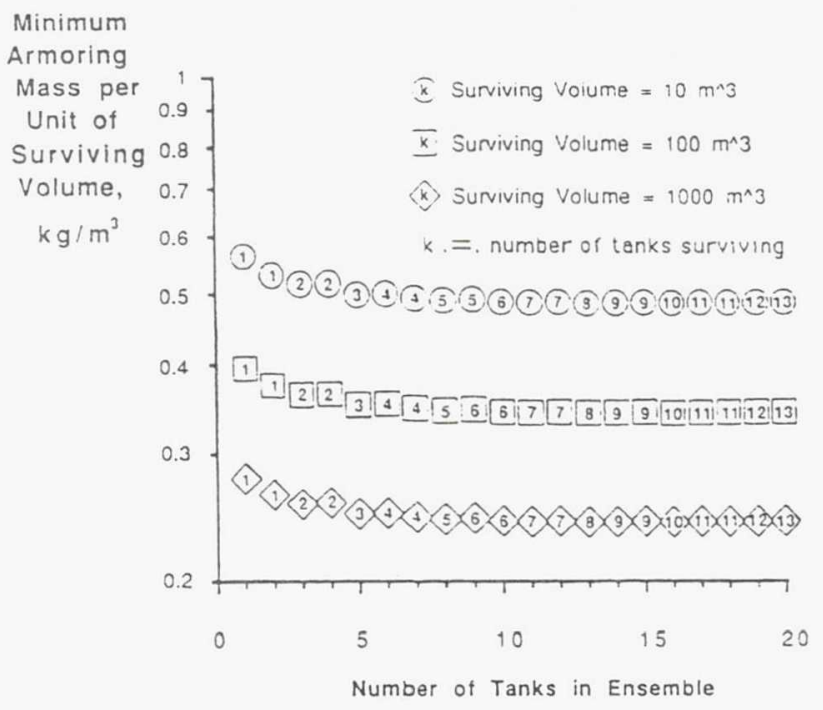

Figure 9.-Bumpered wall armoring ( $\mathrm{S} 1 / \mathrm{d}=50), 0.995$ survival probability, seven year mission. 


\section{REPORT DOCUMENTATION PAGE}

Public reporting burden for this collection of information is estimated to average 1 hour per response, including the time for reviewing instructions, searching existing data sources, gathering and maintaining the data needed, and completing and reviewing the collection of information. Send comments regarding this burden estimate or any other aspect of this collection of information, including suggestions for reducing this burden, to Washington Headquarters Services, Directorate for information Operations and Reports, 1215 Jefferson Davis Highway, Suite 1204, Arlington, VA 22202-4302, and to the Office of Management and Budget, Paperwork Reduction Project (0704-0188), Washington, DC 20503.

\begin{tabular}{|l|r|r|}
\hline 1. AGENCY USE ONLY (Leave blank) & $\begin{array}{r}\text { 2. REPORT DATE } \\
1992\end{array}$ & $\begin{array}{r}\text { 3. REPORT TYPE AND DATES COVERED } \\
\text { Technical Memorandum }\end{array}$ \\
\hline
\end{tabular}

4. TITLE AND SUBTITLE

5. FUNDING NUMBERS

Optimization of Armored Spherical Tanks for Storage on the Lunar Surface

WU-326-81-10

6. AUTHOR(S)

D.J. Bents and D.A. Knight

7. PERFORMING ORGANIZATION NAME(S) AND ADDRESS(ES)

8. PERFORMING ORGANIZATION REPORT NUMBER

National Aeronautics and Space Administration

Lewis Research Center

Cleveland, Ohio 44135-3191

E-7088

9. SPONSORING/MONITORING AGENCY NAMES(S) AND ADDRESS(ES)

10. SPONSORING/MONITORING AGENCY REPORT NUMBER

National Aeronautics and Space Administration

Washington, D.C. 20546-0001

NASA TM-105700

\section{SUPPLEMENTARY NOTES}

Prepared for the 27th Intersociety Energy Conversion Engineering Conference cosponsored by SAE, ACS, AIAA, ASME, IEEE, AIChE, and ANS, San Diego, California, August 3-7, 1992. Responsible person, D.J. Bents, (216) 433-6135.

12a. DISTRIBUTION/AVAILABILITY STATEMENT

12b. DISTRIBUTION CODE

Unclassified - Unlimited

Subject Category 20

13. ABSTRACT (Maximum 200 words)

A redundancy strategy for reducing micrometeroid armoring mass is investigated, with application to cryogenic reactant storage for a regenerative fuel cell (RFC) on the lunar surface. In that micrometeoroid environment, the cryogenic fuel must be protected from loss due to tank puncture. The tankage must have a sufficiently high probability of survival over the length of the mission that the probability of system failure due to tank puncture is low compared to the other mission risk factors. Assuming that a single meteoroid penetration can cause a storage tank to lose its contents, two means are available to raise the probability of surviving micrometeoroid attack to the desired level. One can armor the tanks to a thickness sufficient to reduce probability of penetration of any tank to the desired level; or add extra capacity, in the form of spare tanks, that results in survival of a given number out of the ensemble at the desired level. In this paper a combination of these strategies (armoring and redundancy) is investigated. The objective is to find the optimum combination which yields the lowest shielding mass per cubic meter of surviving fuel out of the original ensemble. The investigation found that, for the volumes of fuel associated with multikilowatt class cryo storage RFC's, and the armoring methodology and meteoroid models used, storage should be fragmented into small individual tanks. Larger installations (more fuel) pay less of a shielding penalty than small installations. For the same survival probability over the same time period, larger volumes will require less armoring mass per unit volume protected.

14. SUBJECT TERMS
Meteoroid armoring; Lunar base; Regenerative fuel cell systems

17. SECURITY CLASSIFICATION OF REPORT

Unclassified
18. SECURITY CLASSIFICATION OF THIS PAGE Unclassified
19. SECURITY CLASSIFICATION OF ABSTRACT Unclassified
15. NUMBER OF PAGES

10

16. PRICE CODE

$\mathrm{AO2}$ 